\title{
Thrombocytopenia in Critically III Patients: Clinical and Laboratorial Behavior and Its Correlation with Short-term Outcome during Hospitalization
}

\author{
Divya Khurana, Shilpa A. Deoke ${ }^{1}$ \\ MBBS Intern, NKP Salve Institute of Medical Sciences and Lata Mangeshkar Hospital, ${ }^{1}$ Department of Medicine, NKP Salve Institute of Medical Sciences and Lata \\ Mangeshkar Hospital, Nagpur, Maharashtra, India
}

\section{Abstract}

Background: Thrombocytopenia, being among the most common laboratory abnormality, found in Intensive Care Unit (ICU) patients is commonly associated with sepsis and disseminated intravascular coagulation. Declining platelet counts are associated with higher mortality rates. Thus, thrombocytopenia can be used as a prognostic marker in critically ill patients. Methodology: A prospective observational study was conducted on patients fulfilling the inclusion criteria and were evaluated for complete medical history, clinical, and laboratorial examination. Short-term outcome of the patient was correlated with thrombocytopenia. Results: The incidence of thrombocytopenia in ICU patients was $37.57 \%$, and mortality was $44 \%$. Higher mortality rate was found among patients with acute febrile illnesses, respiratory diseases, and sepsis $(P=0.08,0.22,0.41$ respectively). The mortality was higher in patients with platelet counts $<100,000 / \mu 1(P=0.0008)$ and whose platelet levels declined on day 3 or $5(P=0.0001)$. Conclusions: Low as well as declining platelet counts are markers of severity of critical patients and are directly related to prognosis and mortality of patients in ICU.

Keywords: Critically ill patients, prognostic marker, thrombocytopenia

\section{INTRODUCTION}

Thrombocytopenia, defined as a platelet count of $<150,000 / \mu 1$, is one of the most common laboratory abnormalities seen in critically ill patients admitted to Intensive Care Unit (ICU); its incidence ranges from $15 \%$ to $60 \%$ in patients admitted to ICU. ${ }^{[1]}$ It is commonly associated with sepsis, disseminated intravascular coagulation (DIC), massive blood transfusion, and chemotherapy. ${ }^{[2,3]}$

Of all the thrombocytopenic patients admitted in ICU, around $50 \%$ of the patients present with thrombocytopenia on admission and rest develop during the hospital stay. ${ }^{[4,5]}$ Thrombocytopenia has been shown to be associated with longer ICU stays, a higher incidence of bleeding events, greater transfusion requirements, and higher mortality..$^{[5,6]}$ The prevalence of major bleeding events such as mucosal bleed is also higher in thrombocytopenic patients. Previous studies have shown that thrombocytopenia is itself a reliable prognostic marker for mortality; furthermore, declining platelet levels during the ICU stay also serves as independent prognostic markers

\begin{tabular}{|l|l|}
\hline \multicolumn{3}{|c|}{ Access this article online } \\
\hline Quick Response Code: & Website: \\
\hline & www.ijccm.org \\
\cline { 2 - 2 } & \\
\hline
\end{tabular}

for mortality. ${ }^{[1,6]}$ Prolonged thrombocytopenia and failure to nonresolution of thrombocytopenia have also been shown to be associated with increased mortality ${ }^{[5]}$ A platelet count above $150,000 / \mu l$ is considered as a good outcome predictor. ${ }^{[3]}$

Therefore, in our study, we evaluated the clinical profile of thrombocytopenic patients and correlated thrombocytopenia and decreasing levels of platelet count with short-term outcome of patient in terms of mortality or survival and/or duration of ICU stay.

\section{Objectives}

1. To know the rate of occurrence of thrombocytopenia in ICU patients

Address for correspondence: Dr. Divya Khurana, NKP Salve Institute of Medical Sciences and Lata Mangeshkar Hospital, Hingna, Nagpur - 440 019, Maharashtra, India. E-mail: drishtikhurana94@gmail.com

This is an open access article distributed under the terms of the Creative Commons Attribution-NonCommercial-ShareAlike 3.0 License, which allows others to remix, tweak, and build upon the work non-commercially, as long as the author is credited and the new creations are licensed under the identical terms.

For reprints contact: reprints@medknow.com

How to cite this article: Khurana D, Deoke SA. Thrombocytopenia in critically ill patients: Clinical and laboratorial behavior and its correlation with short-term outcome during hospitalization. Indian J Crit Care Med 2017;21:861-4. 
2. To study clinical profile of patients presenting with thrombocytopenia

3. To correlate thrombocytopenia with short-term outcomes (mortality or survival) during the hospital stay.

\section{Methodology}

\section{Study design}

After approval by the institutional ethics committee, a prospective observational study was conducted on patients admitted to medical ICU within 2 months.

\section{Sample size}

Consecutive fifty patients admitted to medical ICU with thrombocytopenia or those who developed it anytime during the ICU stay during the period of study were included in our study. In case a patient was admitted to ICU multiple times, only first admission was taken into account.

\section{Method}

All patients diagnosed with thrombocytopenia on admission or anytime during the stay in ICU were evaluated for 5 days by complete medical history, clinical, and laboratorial examination after obtaining written consent from the patient or spouse or first-degree relative (in case of patients with altered mental state). In case of patients developing thrombocytopenia after admission to ICU, the day of development of thrombocytopenia was considered as day 1 and was evaluated for the next 5 days in ICU.

The data to be evaluated included demographic details of patient, history of present illness, drug history, comorbidities, cause of admission to ICU, treatment taken, length of ICU stay as well as total hospitalization (in number of days), blood sugar levels, complete blood count, kidney function tests, liver function tests, coagulation profile, and clinical examination data.

Platelet count assessment was done on day 1, 3, and 5 after admission to ICU. Thrombocytopenia was considered as platelet count of $<150,000 / \mu 1$ and recovery was defined as platelet count of $>150,000 / \mu 1$ after developing thrombocytopenia. The last platelet count was done day 5 for survivours and day of death in nonsurvivours if death occurred before the fifth day. In case of availability of more than one platelet count of a patient on a single day, the lower value was taken into consideration.

After collecting above data for 5 days, patient's duration of hospitalization (in number of days) was recorded if patient stayed in hospital for more than 5 days.

After data collection and analysis, rate of occurrence of thrombocytopenia in patients admitted to medical ICU was calculated. Clinical manifestations of thrombocytopenia seen in patients were recorded, and short-term outcome of these patients (mortality or recovery followed by discharge from the hospital or prolonged hospitalization) was assessed and correlated with thrombocytopenia.

\section{Inclusion criteria}

1. Critically ill patients admitted to medical ICU with thrombocytopenia on admission or those who developed it anytime during the ICU stay

2. Patients and/or spouse with above criteria who are willing to participate in the study.

\section{Exclusion criteria}

1. Patients with clinical suspicion of thrombocytopenia due to drugs such as heparin and quinine

2. Pregnancy

3. Patients who have undergone chemotherapy or radiotherapy in the last 30 days

4. Clinical suspicion of hematological disorders such as leukemia, thrombotic thrombocytopenic purpura, and hypersplenism per se

5. Patients receiving massive blood transfusion (>10 units/day).

\section{RESULTS}

Out of 173 patients admitted to ICU during our study period, 65 patients had thrombocytopenia either on admission or during the ICU stay. Out of these, 50 patients met our inclusion criteria and were included in the study. The incidence of thrombocytopenia in ICU patients was $37.57 \%$. The range of platelet counts was between 0.35 and 1.49 lacs $/ \mu 1$.

Out of 50 patients, 22 patients died during their hospital stay, mortality being $44 \%$.

Table 1 and Figure 1 shows age-gender distribution in the studied population.

On studying clinical profile of these patients, a higher mortality rate was found among patients who presented to ICU with acute febrile illnesses $(80 \%)$, respiratory diseases $(66.66 \%)$, and sepsis $(62.5 \%)(P=0.08,0.22,0.41$, respectively) [Table 2].

On admission, 39 patients (78\%) had thrombocytopenia while 11 patients $(22 \%)$ developed it during the ICU stay. However, the mortality rates among these two groups were not statistically significant with $P=0.20$ [Table 3].

To correlate levels of thrombocytopenia with short-term outcomes of patients, patients were divided into two groups according to the level of thrombocytopenia. The mortality was higher in patients with platelet counts $<100,000 / \mu 1$ $(P=0.0008)[$ Table 4$]$ and in those whose platelet levels

Table 1: Age-gender distribution in study population

\begin{tabular}{lcc}
\hline Age (years) & \multicolumn{2}{c}{ Gender $(\boldsymbol{n}=\mathbf{5 0})$} \\
\cline { 2 - 3 } & Male, $\boldsymbol{n}(\%)$ & Female, $\boldsymbol{n}(\mathbf{\%})$ \\
\hline $21-40$ & $20(40)$ & $6(12)$ \\
$41-60$ & $11(22)$ & $3(6)$ \\
$>60$ & $5(10)$ & $5(10)$ \\
Total $(n=50)$ & $36(72)$ & $14(28)$ \\
\hline
\end{tabular}


declined on day 3 or day 5 than those whose platelet counts improved during the hospitalization $(P=0.0001)$ [Table 5].

Out of 22 patients who died, 15 patients $(68.18 \%)$ died on day 3. Out of these 15 patients, 10 had platelet counts $<100,000 / \mu 1(P=0.29)$ [Table 6].

\section{Discussion}

After analyzing the data, the incidence of thrombocytopenia in critically ill patients was found to be $37.57 \%$. Previous studies have shown that its incidence ranges from $15 \%$ to $60 \%$ in patients admitted to ICU. ${ }^{[1]}$

The mortality rate in critically ill thrombocytopenic patients was $44 \%$.

Previous studies have shown a higher mortality rate among patients who had thrombocytopenia on admission than those who developed it later during hospital stay. ${ }^{[7]}$ In our study, though statistically insignificant, a similar result was found. Out of 39 patients who presented with thrombocytopenia on admission, 19 patients (48\%) died during the hospitalization and those who developed thrombocytopenia later on during the hospitalization mortality rate was $27.27 \%$ among them $(P=0.20)$ [Table 3 ].

On studying the clinical profile of these patients, a higher mortality was found among patients diagnosed with acute febrile illness, sepsis, and respiratory illness along with thrombocytopenia [Figure 2]. The systemic inflammatory response syndrome and sepsis are among the leading causes of hospitalization and ICU mortality as are the leading causes of thrombocytopenia in critically ill patients. ${ }^{[7]}$ However, in our study, the highest mortality rate was found in patients with acute febrile illness (malaria, dengue and other viral fevers). A higher mortality rate among these patients could be attributed to multisystem failure as out of 5 patients, 3 had multiple organ failure.

Bleeding manifestations such as mucosal bleeds are common in thrombocytopenic patients. In our study, we could not find any such significant bleeding manifestations. A higher

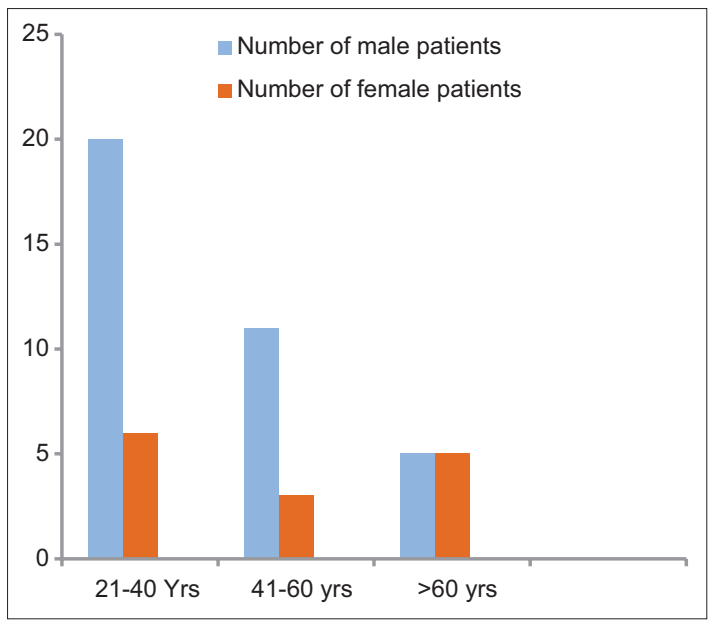

Figure 1: Age-gender distribution in study population mortality on day $3(68.18 \%, n=22)$ of ICU admission could be the possible explanation for this as the patients died before such manifestations could occur.

Previous studies have shown that progressive decrease in platelet count is also associated with a worse prognosis, ${ }^{[8]}$ as well as platelet count above 150,000 appears to be a predictor of good outcome. ${ }^{[3]}$ Our study also showed a higher mortality rate in patients whose platelet levels declined on day 3 and/or

\begin{tabular}{lccc}
\hline \multicolumn{3}{l}{$\begin{array}{l}\text { Table 2: Distribution of patients according to clinical } \\
\text { diagnosis and associated mortality rates }\end{array}$} \\
\hline Diagnosis & $\begin{array}{c}\text { Survivors } \\
(\boldsymbol{n = 2 9 )}\end{array}$ & $\begin{array}{c}\text { Nonsurvivors } \\
(\boldsymbol{n = 2 1 )}, \boldsymbol{n}(\%)\end{array}$ & $\begin{array}{c}\boldsymbol{P} \\
\text { (Z-test) }\end{array}$ \\
\hline Sepsis $(n=8)$ & 3 & $5(62.5)$ & 0.41 \\
Acute febrile illness $(n=5)$ & 1 & $4(80)$ & 0.08 \\
Neurological $(n=5)$ & 4 & $1(20)$ & 0.31 \\
Abdominal $(n=6)$ & 2 & $4(66.66)$ & 0.22 \\
Cardiovascular $(n=20)$ & 13 & $7(35)$ & 0.52 \\
Respiratory $(n=5)$ & 5 & 0 & 0.057 \\
Others $(n=2)$ & 1 & $1(50)$ & 0.81 \\
\hline
\end{tabular}

\section{Table 3: Association of mortality and the time of} development of thrombocytopenia

\begin{tabular}{lcccc}
\hline $\begin{array}{l}\text { Time of development } \\
\text { of thrombocytopenia }\end{array}$ & Survivors & $\begin{array}{c}\text { Nonsurvivors, } \\
\boldsymbol{n}(\%)\end{array}$ & $\chi^{2}$ & $\boldsymbol{P}$ \\
\hline $\begin{array}{l}\text { Thrombocytopenia on } \\
\text { admission }(n=39)\end{array}$ & 20 & $19(48)$ & 1.60 & 0.20 \\
$\begin{array}{l}\text { Thrombocytopenia } \\
\text { after admission }(n=11)\end{array}$ & 8 & $3(27.27)$ & & \\
Total $(n=50)$ & 28 & 22 & & \\
\hline
\end{tabular}

Table 4: Distribution of patients according to level of thrombocytopenia in survivors and nonsurvivors

\begin{tabular}{lcccc}
\hline Platelet count (lacs) & Survivors & Nonsurvivors & $\chi^{2}$ & $\boldsymbol{P}$ \\
\hline$<1$ & 6 & 15 & 11.055 & 0.0008 \\
$1-1.5$ & 22 & 7 & & \\
\hline
\end{tabular}

Table 5: Comparison of platelet trends in day 5 survivors $(n=32)$

\begin{tabular}{lcccc}
\hline Platelet count & Survivors & Nonsurvivors & $\chi^{2}$ & $\boldsymbol{P}$ \\
\hline Declining & 2 & 5 & 13.93 & 0.0001 \\
Increasing & 25 & 2 & & \\
\hline
\end{tabular}

\begin{tabular}{lcccc}
\hline $\begin{array}{l}\text { Table 6: Comparison of platelet trends in nonsurvivors } \\
(\boldsymbol{n}=\mathbf{2 2})\end{array}$ & \multicolumn{3}{l}{} \\
\hline $\begin{array}{l}\text { Platelet } \\
\text { counts (lacs) }\end{array}$ & $\begin{array}{c}\text { Number of days of hospitalization } \\
\text { in nonsurvivors }\end{array}$ & $\chi^{2}$ & $\boldsymbol{P}$ \\
\cline { 2 - 3 } & $\mathbf{3}$ days & $>\mathbf{3}$ days & & \\
\hline$<1$ & 10 & 3 & 1.11 & 0.29 \\
$1-1.49$ & 5 & 4 & & \\
\hline
\end{tabular}




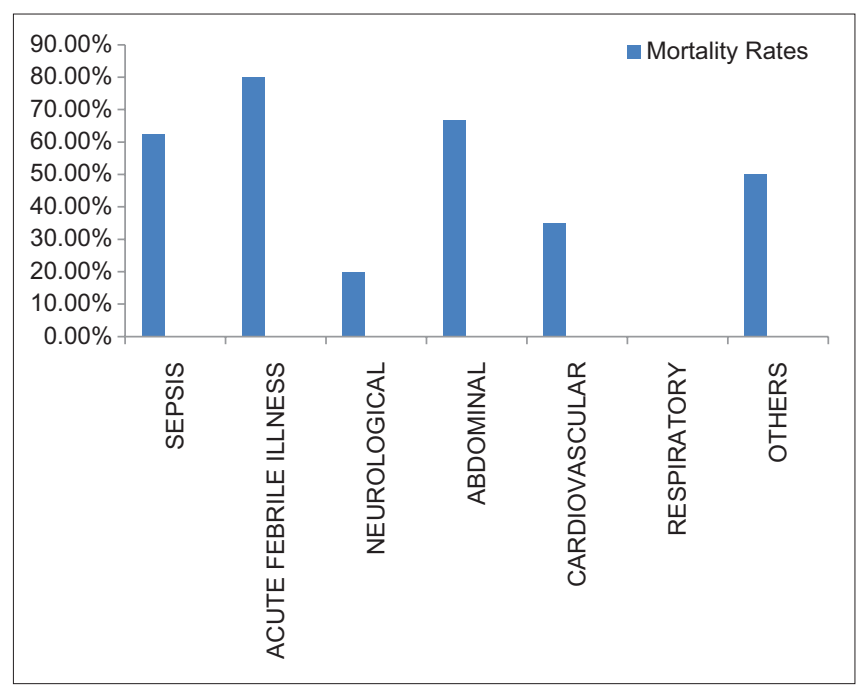

Figure 2: Distribution of patients according to clinical diagnosis and associated mortality rates

\begin{tabular}{|c|c|c|c|c|}
\hline \multirow[t]{2}{*}{ Platelet count (lacs) } & \multicolumn{2}{|c|}{ Duration of ICU stay } & \multirow[t]{2}{*}{$\chi^{2}$} & \multirow[t]{2}{*}{$P$} \\
\hline & $<3$ days & $>3$ days & & \\
\hline$<<1$ & 1 & 2 & 1.29 & 0.255 \\
\hline $1-1.5$ & 18 & 9 & & \\
\hline
\end{tabular}

ICU: Intensive Care Unit

day 5 than those whose platelet counts improved during the hospitalization ( $P=0.0001)$ [Table 5]. Thus, declining platelet levels over a period of time during hospitalization may serve as an independent prognostic marker for mortality.

Our study also revealed that mortality was higher in patients with platelet counts $<100,000 / \mu l(P=0.0008)$. This could also be considered as an independent prognostic marker for mortality. On correlating the platelet levels with duration of ICU stay, no significant association was found $(P=0.255)$ [Table 7].

In conclusion, low platelet count on admission as well as declining platelet counts are not just the markers of severity of critical patients and progression of the underlying disease but is also directly related to the prognosis and mortality of patients in ICU.

\section{Conclusions}

Platelets play a major role in hemostasis and are markers of DIC. In critically ill patients, they are markers of hematological abnormality. The diseases causing thrombocytopenia, rather than thrombocytopenia per se, frequently lead to a fatal outcome. A significant decrease in platelet count is an independent alarming risk factor for mortality. Therefore, failure to identify and correct thrombocytopenia may lead to deleterious complications such as massive hemorrhage and subsequently multiorgan failure.

Since platelet count assessment is a simple, rapid, cheap, and reliable test, it can be done regularly to monitor the status of critically ill patients without much increase in the investigation cost to the patient so that better measures for management and prevention of complications can be taken.

\section{Acknowledgment}

We are thankful to Mr. Jaydeep Nayse, Statistician, NKP Salve Institute of Medical Sciences, Lata Mangeshkar Hospital, Nagpur, Maharashtra, for his valuable assistance in statistical analysis.

\section{Financial support and sponsorship}

Nil.

\section{Conflicts of interest}

There are no conflicts of interest.

\section{RefERENCES}

1. Elgohary TS, Zaghla HE, Azab AM, Hagag T. Role of thrombocytopenia as an independent prognostic marker in the critically ill patients with multiorganfailure. Med J Cairo Univ 2011;79:1-9.

2. Chakraverty R, Davidson S, Peggs K, Stross P, Garrard C, Littlewood TJ, et al. The incidence and cause of coagulopathies in an intensive care population. Br J Haematol 1996;93:460-3.

3. Stéphan F, Hollande J, Richard O, Cheffi A, Maier-Redelsperger M, Flahault A, et al. Thrombocytopenia in a surgical ICU. Chest 1999;115:1363-70.

4. Crowther MA, Cook DJ, Meade MO, Griffith LE, Guyatt GH, Arnold DM, et al. Thrombocytopenia in medical-surgical critically ill patients: Prevalence, incidence, and risk factors. J Crit Care 2005;20:348-53.

5. Akca S, Haji-Michael P, de Mendonça A, Suter P, Levi M, Vincent JL, et al. Time course of platelet counts in critically ill patients. Crit Care Med 2002;30:753-6.

6. Strauss R, Wehler M, Mehler K, Kreutzer D, Koebnick C, Hahn EG, et al. Thrombocytopenia in patients in the medical Intensive Care Unit: Bleeding prevalence, transfusion requirements, and outcome. Crit Care Med 2002;30:1765-71.

7. Vanderschueren S, De Weerdt A, Malbrain M, Vankersschaever D, Frans E, Wilmer A, et al. Thrombocytopenia and prognosis in intensive care. Crit Care Med 2000;28:1871-6.

8. Boechat TD, Silveira MF, Faviere W, Macedo GL. Thrombocytopenia in sepsis: An important prognosis factor. Rev Bras Ter Intensiva 2012;24:35-42. 